\title{
Desempenho dos Arranjos Institucionais e Minimização dos Custos de Transação: transações entre produtores e fecularias de mandioca
}

Olivier Vilpoux ${ }^{1}$

Resumo: No Brasil, a falta de competitividade do setor de fécula de mandioca em relação ao amido de milho é explicada pelas dificuldades em obter matériaprima - raízes de mandioca - em quantidades e preços estáveis. A resolução desses problemas envolve a adoção de arranjos institucionais que estabilizam as transações entre produtores e industriais. A análise de 37 fecularias permitiu avaliar as características das transações e o desempenho dos arranjos adotados, medido por meio da capacidade das empresas em estabilizar seu fornecimento de matéria-prima. Os arranjos institucionais encontrados foram classificados em seis tipos, do mercado até a integração vertical, em função do nível de garantia oferecido para entrega de matéria-prima. Apesar da existência de especificidade dos ativos e de incerteza, as empresas preferem as transações via mercado spot, arranjo identificado como menos eficiente. A incerteza ligada ao funcionamento das instituições aumenta os custos de transação dos arranjos contratuais, o que explica a preferência dos atores pelo mercado. Os acordos contratuais com garantias intermediárias e fortes foram mais eficientes, mas com maiores custos de transação. Os resultados indicam dois caminhos para melhorar a competitividade do setor: (1) melhoria na eficiência do mercado, sistema com menores custos de transação; (2) redução dos custos de transação dos arranjos institucionais com maiores garantias, o que proporcionaria sistemas mais eficientes. Enquanto nenhuma dessas soluções for adotada, as fecularias brasileiras continuarão com arranjos de baixos custos de transação, mas fraco desempenho.

Palavras-chave: Economia dos Custos de Transação, nova economia das instituições, arranjos institucionais múltiplos, garantias informais, eficiência.

1 Docente do mestrado em Desenvolvimento Local, Universidade Católica de Campo Grande (UCDB), Mato Grosso do Sul. E-mail: vilpoux@ucdb.br 
Desempenho dos Arranjos Institucionais e Minimização dos Custos de Transação: transações entre produtores e fecularias de mandioca

\begin{abstract}
The lack of competitiveness of Brazilian cassava starch industry in relation to corn starch is explained by the difficulty to obtain raw material (cassava roots) in stable quantities and stable prices. The resolution of these problems involves the adoption of governance systems that stabilize the transactions between producers and processing units. The analysis of 37 factories has allowed the evaluation of transaction costs and the performance of adopted governance systems, calculated from the ability to stabilize raw material supply. The governance systems were classified into six groups, from spot market to vertical integration, depending on the level of warranty offered in the delivery of raw material. Despite the identification of asset specificity and transaction risk, cassava starch companies prefer market transaction, a governance system identified as less efficient. The low efficiency of institutions increase transaction costs of contractual governances, which can explain the preference for the market. Contractual agreements with intermediaries and strong warranties are more efficient, but with high transaction costs. These results indicate two ways to improve the competitiveness of the cassava starch industry: (1) improvement in market efficiency, system with lower transaction costs, (2) reduction of transaction costs for governance systems with more warranties, which might generates more efficient systems. While neither of the two solutions is adopted, Brazilian cassava starch industry continues to adopt low transaction costs, but with weak efficiency.
\end{abstract}

Key-words: Transaction costs economy, new economy of institutions, multiple governance systems, informal warranty, efficiency.

Classificação JEL: D23, L14, L22.

\title{
1. Introdução
}

A mandioca (Manihot esculenta Crantz) é uma planta originária do Brasil, cuja cultura está presente na maioria dos países tropicais. Segundo o IBGE (2010), a produção nacional na safra em 2009 foi estimada em 26,6 milhões de toneladas, com rendimento médio de 14,1 toneladas de raízes por hectare.

A mandioca é cultivada em todo o território nacional, embora alguns estados concentrem a maioria da produção. Pode ser consumida na alimentação humana ou industrializada. No uso culinário, a mandioca recebe nomes regionais de mandioca de mesa, aipim ou macaxeira. No uso industrial, pode ser transformada em farinha, fécula e polvilho azedo. A fécula é um commodity que compete em nível internacional com os amidos de milho, trigo e a fécula de batata $^{2}$, que possuem propriedades similares. A fécula de mandioca é o principal

2 Tradicionalmente, a palavra fécula define o produto obtido a partir de raízes e tubérculos (batata, mandioca). O amido é aquele oriundo de frutas e cereais (trigo, milho). 
amido exportado no mundo e constitui uma das primeiras fontes de divisas da Tailândia. A partir da fécula de mandioca podem ser produzidos diversos derivados, ou amidos modificados, utilizados nas indústrias papeleira, química e alimentícia, entre outras.

Considerando-se a fase de produção primária e o processamento de farinha e de fécula de mandioca, estima-se que o setor gera, no Brasil, em torno de um milhão de empregos diretos, concentrados no meio rural (CARDOSO e LEAL, 1999, apud CARDOSO, 2003).

Antes considerada uma cultura de baixo valor agregado, destinada ao processamento de alimentos baratos para as camadas mais pobres da população, a mandioca conheceu uma profunda mudança de imagem no Brasil desde o inicio dos anos 2000. Impulsionada pela produção de fécula nos estados do Paraná, Mato Grosso do Sul e São Paulo, ela está sendo associada à criação de empregos no meio rural, com possível reversão do êxodo característico de muitas regióes do interior do País.

Apesar do crescimento do número de empreendimentos desde o início dos anos 2000, o setor não consegue maior êxito e a produção nacional do fim da primeira década do milênio permanece inferior à produção dos anos 2001 e 2002 (ABAM, 2010). O Brasil é um dos maiores produtores mundiais de fécula, atrás da Tailândia e Indonésia, mas suas exportações permanecem insignificantes. Em 2008, a Câmara Setorial de Mandioca do Estado de Mato Grosso do Sul identificou a instabilidade da produção como um dos fatores responsáveis pela falta de competitividade do setor.

Vilpoux (1997) já relatava a importância desse fator ao analisar os setores de farinha, fécula e polvilho azedo nas regiões Sul, Sudeste e Centro-Oeste do País. O autor evidenciou a instabilidade da oferta e dos níveis de preços como os principais fatores limitantes do crescimento do setor e emitiu a hipótese de que a falta de competitividade da cadeia de mandioca podia ser explicada por arranjos institucionais inadequados entre produtores agrícolas e processadores. Para o autor, essa inadequação dos arranjos adotados pelas fecularias na compra de matéria-prima tinha repercussões diretas nas empresas, com ausência de planejamento da produção e grande flutuação de preços, fatores que dificultam a competitividade com o milho, no Brasil, ou com a fécula da Tailândia, no mercado internacional.

Goebel (2005) confirma essa situação com dados mais recentes e afirma que a quantidade de matéria-prima disponível é extremamente volátil e fonte de dificuldades em todo o setor. $\mathrm{O}$ autor reforça a importância da análise do processo de organização e da coordenação entre os agentes envolvidos nas transações entre a produção de matéria-prima e o processamento. Enfatiza ainda a necessidade de entender os aspectos que condicionam a dinâmica deste sistema, marcado por disparidades entre oferta e demanda, o que ocasiona fortes flutuações de preços. 
Desempenho dos Arranjos Institucionais e Minimização dos Custos de Transação: transações entre produtores e fecularias de mandioca

Baseada nessa constatação, a hipótese adotada foi de que, no setor de fécula de mandioca, os arranjos institucionais que permitem maior controle de abastecimento e estabilidade da produção não são os mais adotados pelas empresas, o que explicaria as dificuldades encontradas. Com base nessa idéia, a pesquisa objetiva relacionar os arranjos institucionais adotados nas transações entre produtores e fecularias ao controle de abastecimento das empresas e explicar, por meio da economia dos custos de transação, as razões da adoção de arranjos menos eficientes na estabilização do setor.

\section{Justificativa}

O interesse crescente pela fécula contribuiu para a aceleração regular da produção até 2002 (Figura 1). Nos dois anos seguintes, a produção no Brasil diminuiu em decorrência da falta de matéria-prima, provocada principalmente pela forma inadequada de organização da cadeia agroindustrial. Em 2005 e 2006, segundo dados publicados pela Associação Brasileira dos Produtores de Amido de Mandioca (Abam), em parceria com o Centro de Estudos Avançados em Economia Aplicada (Cepea), a produção cresceu respectivamente 39,1\% e $12,8 \%$ em relação ao ano anterior (ABAM, 2010). Ainda assim, a produção de 2006 permanecia $17,3 \%$ inferior àquela de 2002. Em 2007, a produção de fécula de mandioca no País apresentou queda de 5,1\% , antes de voltar a crescer $4 \%$ em 2008 , repetindo os ciclos de instabilidade dos anos anteriores e confirmando a incapacidade do setor de retomar o ciclo de crescimento interrompido em 2002.

Figura 1. Evolução da produção de fécula de mandioca no Brasil, de 1990 a 2008.

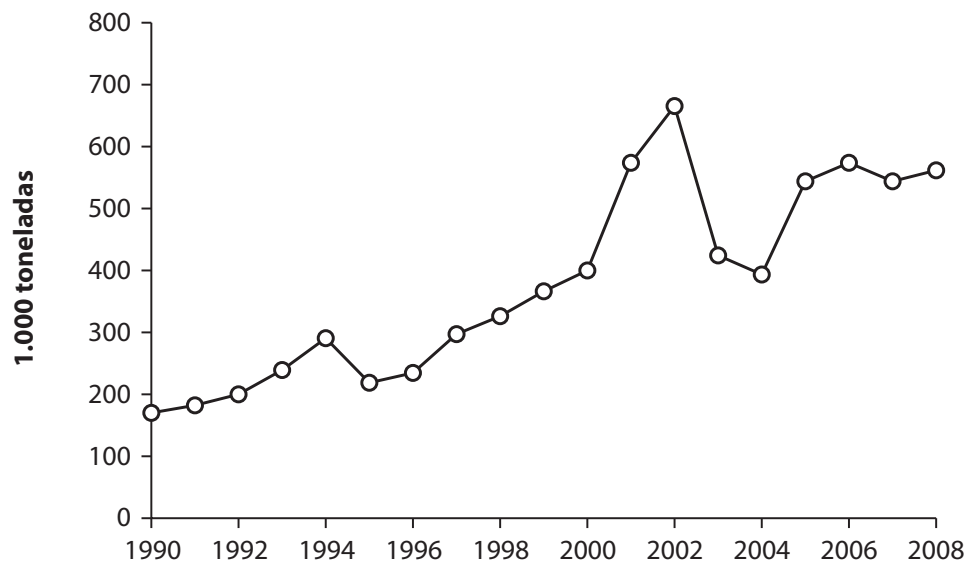

Fonte: Abam (2010). 
Entre 2002 e 2006, a capacidade instalada de produção de fécula de mandioca no Brasil aumentou $30 \%$, enquanto a produção de 2006 permaneceu $15 \%$ inferior à de 2002 (VILPOUX, 2006). Goebel (2005) analisou o setor na microrregião oeste do Paraná, confirmou a existência de capacidade ociosa elevada e evidenciou fortes oscilações nas quantidades produzidas de mandioca, com crescimento elevado da capacidade de industrialização. O parque produtivo de processamento da microrregião citada apresenta claro indício de expansão, sem o correspondente aumento da oferta de matéria-prima, o que demonstra, para o autor, uma falha de coordenação no setor.

\subsection{Instabilidade dos preços como fator de desestabilização do setor}

Os preços de mandioca são submetidos a grandes variações sazonais e alcançam um nível mínimo entre maio e agosto, meses que representam o pico da colheita, antes de subir novamente no verão. Além das variações sazonais, os preços são influenciados pelos preços praticados no momento da safra anterior, e por eventos dificilmente previsíveis, como as condições climáticas no Sul, os preços do milho e da soja etc. Entre esses, destaca-se o clima no Nordeste, grande região produtora de mandioca e consumidora de farinha (VILPOUX, 1997; 2006). A Figura 2 apresenta a evolução dos preços de mandioca nos últimos anos, em valores nominais e corrigidos.

Figura 2. Evolução dos preços médios da mandioca, à vista, pagos aos produtores, entre julho de 1994 e novembro de 2009, nos estados de Mato Grosso do Sul,

Paraná e São Paulo.

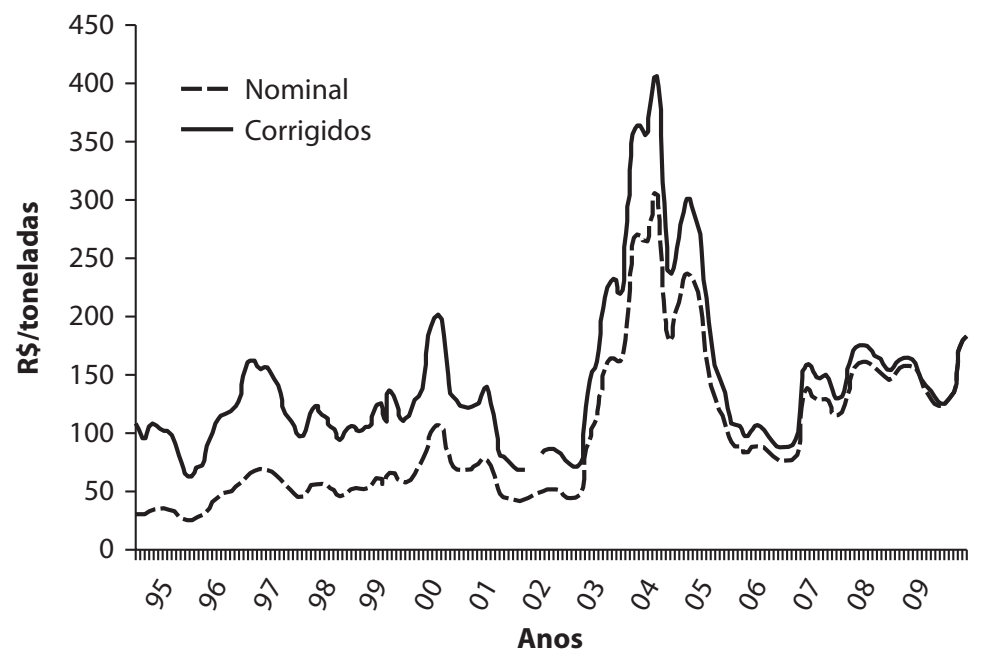

Fonte: Vilpoux (2006) e Cepea (2010). 
Desempenho dos Arranjos Institucionais e Minimização dos Custos de Transação: transações entre produtores e fecularias de mandioca

As grandes variações de preços prejudicam muito o setor. Em 2001 e 2002, os preços atingiram patamares muito baixos, com margens nulas ou negativas para os agricultores (VILPOUX, 2006). Nos dois anos que sucederam estes, os valores atingiram picos anormalmente elevados, antes de cair novamente em 2005 e 2006 para patamares similares aos de 2002. No final de 2006 e início de 2007, os preços de raízes de mandioca voltaram a subir, repetindo os ciclos tradicionais de alto e baixo de 18 a 24 meses, o que indica a forte influência dos preços praticados na safra sobre os preços da temporada seguinte.

As grandes variações nos preços da mandioca repercutem nos da fécula, com variações que prejudicam a atuação das empresas no mercado. Takitane et al. (1996) relataram que a viabilidade econômica das indústrias era ameaçada pelas grandes variações na oferta e nos preços da raiz. O aumento dos preços estimula o plantio, sem planejamento por parte de agricultores, o que resulta em excesso da oferta, com queda sucessiva nos preços e perda de motivação de agricultores em relação à cultura.

Vilpoux (2006) comenta que, entre o segundo semestre de 2001 e o final de 2002 , o preço da fécula nacional permaneceu abaixo de US\$ 150/tonelada, preço FOB, nível baixo se comparado com o preço internacional do amido, mesmo em relação à fécula de mandioca da Tailândia, que ocupa quase a totalidade do mercado internacional deste produto. $\mathrm{Na}$ ocasião, as exportações para a América Latina e a Europa cresceram, e a fécula atingiu novos mercados em nível nacional, que antes eram ocupados pelo amido de milho.

Em 2003 e 2004, com a escassez de produto, os preços da fécula de mandioca no Brasil ultrapassaram US\$ 500/tonelada. Esse aumento levou à perda dos mercados nacionais conquistados nos anos anteriores e à retirada das empresas brasileiras do mercado internacional (VILPOUX, 2006).

Em2004, para evitar a repetição desses problemase recuperar a competitividade do setor, as fecularias de mandioca decidiram implantar contratos de fornecimento com garantia de compra e fixação de um preço mínimo, em $\mathrm{R} \$ 120$ por tonelada de mandioca. Essa tentativa visava estabilizar a produção e evitar as grandes flutuações dos anos anteriores, nos quais o preço da raiz variou de 50 até mais de 300 reais por tonelada (Figura 2). O preço mínimo fixado nos contratos foi atingido logo nos primeiros meses de 2005 e, a partir de maio do mesmo ano, os preços nos estados das regióes Sul, Sudeste e Centro-Oeste ficaram abaixo de R\$ $120 / t$, atingindo menos de $R \$ 80 / t$ em maio de 2006. A queda, abaixo dos limites contratuais, evidenciou a dificuldade de implantar arranjos via contratos para o fornecimento de matéria-prima. As consequências dessa dificuldade para o setor justificam entender as razões da falha no funcionamento de arranjos contratuais.

Goebel (2005) encontrou as mesmas dificuldades com contratos na microrregião do Oeste do Paraná, que o autor explicou pelas elevadas oscilações de preços e pela assimetria de informações. No momento em que a agroindústria processadora firma um contrato, este não garante a entrega 
da raiz para a fecularia. Dos mandiocultores pesquisados por Goebel que já utilizaram contratos, $22 \%$ entregaram a mandioca colhida para empresas com as quais não haviam feito contrato, sem receber penalidade alguma por isso. A principal causa da quebra de contratos por parte do produtor rural estava relacionada à concorrência através de preço.

\section{Revisão bibliográfica}

Numa primeira parte, a revisão da economia dos custos de transação, abordagem metodológica indispensável para identificar os tipos de arranjos institucionais e as características das transações que influenciam na adoção de um determinado arranjo institucional, é apresentada. Logo, segue a revisão da literatura sobre a análise institucional múltipla, particularidade encontrada no setor de fécula de mandioca, no qual colaboram juntos vários arranjos institucionais para o mesmo tipo de transação.

\subsection{Economia dos Custos de Transação (ECT)}

A teoria da ECT pode ser considerada um braço da Nova Economia Institucional (NEI). Williamson (1985) a diferencia de outras teorias que estudam a economia das organizações ao apontar seu caráter microanalítico, incorporar os pressupostos comportamentais em sua análise, considerar relevantes os investimentos em ativos específicos e reconhecer a firma como uma estrutura de governança e não como mera função de produção.

Williamson (1985) afirma, baseado no artigo pioneiro de Coase, publicado em 1937, que o pressuposto neoclássico de custo de transação igual à zero é uma ficção. Os arranjos institucionais surgem como resposta à necessidade de minimização de custos (de transação e de produção), sendo a internalização das transações resultado da comparação entre os custos hierárquicos e burocráticos internos à firma, em relação aos custos via mercado.

A compreensão da ECT envolve a aceitação dos pressupostos comportamentais de racionalidade limitada e oportunismo. Conforme Azevedo (1996), a racionalidade limitada está relacionada à incompletude dos contratos, na proporção em que alguns elementos da transação não são contratados $e x$-ante. Por outro lado, o comportamento oportunista dos agentes leva à renegociação e, eventualmente, a disputas e rompimentos ex-post. Este comportamento poderá ser mais ou menos prejudicial à relação contratual, implicando em custos de transação. Pode-se afirmar que racionalidade limitada e oportunismo constituem a base estrutural da ECT.

Estabelece-se, assim, por meio de um aumento crescente nos custos de transação, um fluxo cujos extremos são exemplificados pelas relações de 
Desempenho dos Arranjos Institucionais e Minimização dos Custos de Transação: transações entre produtores e fecularias de mandioca

mercado e pela integração vertical. De um lado, encontra-se o mercado spot, no qual a "mão invisível" de Adam Smith se faz presente. Os agentes econômicos seguem seus interesses, desenvolvem-se relações de curto prazo, tendo o preço como termômetro para as interações de mercado. As transações no mercado spot são marcadas pela ausência de relações contínuas entre os atores. Em outro extremo, tem-se a integração vertical, na qual os agentes econômicos passam a fazer parte da mesma entidade, o que facilita a coordenação entre eles e elimina a incerteza ligada à transação. Para a ECT, entre o mercado spot e a integração vertical se localizam as formas híbridas, em que a cooperação é construída pelo interesse mútuo dos agentes envolvidos nas trocas econômicas, constituindo-se relações de médio ou longo prazo que beneficiem ambas as partes.

$\mathrm{Na}$ ECT, as formas híbridas são constituídas de relações contratuais. Fiani (2002) descreve quatro tipos de contratos: os de curto prazo, sem flexibilidade, destinados a resolver uma necessidade presente; os que especificam uma performance no futuro; os que especificam uma performance futura, condicionada à ocorrência de eventos anteriormente definidos, e os que oferecem o direito de escolher a performance no futuro, entre um conjunto de performances estipuladas previamente (relação de autoridade).

Para Ménard (2004), o efeito da reputação é importante nas formas híbridas. A reputação é facilitada pela repetição das transações entre atores. Uma característica fundamental nas formas híbridas é a mistura entre dependência mútua e necessidade de continuidade nas relações. Para o autor, os arranjos que possuem essas características funcionam entre o mercado e a hierarquia e podem ser formais ou informais.

De acordo com Peterson, Wysocki e Stephen (2001), na medida em que há movimento do mercado spot para a integração vertical, a mão invisível de Adam Smith cede espaço para os esforços de coordenação, que assumem sua condição máxima na integração vertical, na busca da redução dos custos de transação. No entanto, como afirma Pondé (2002), a organização das transações no interior de uma empresa não elimina o oportunismo, apenas tenta controlá-lo através da hierarquia.

São três os atributos de transação considerados pela ECT, que influenciam os sistemas de governança adotados: frequência, incerteza e especificidade dos ativos. A frequência relaciona-se com a recorrência ou regularidade da transação. $\mathrm{O}$ segundo atributo identifica-se com o grau de incerteza das transações, relacionado à disponibilidade de informações e ao comportamento oportunista dos indivíduos. O terceiro é a especificidade dos ativos, relacionada aos custos advindos da impossibilidade de alocação alternativa daquele ativo em outra transação qualquer. Segundo Farina et al. (1997, apud PITELLI, 2004), os ativos específicos são aqueles que não podem ser reempregáveis sem perda de valor, tornando o investimento arriscado e com custos de transação. A especificidade dos ativos cria dependência entre os participantes da transação. 
Para Williamson (2005), essa dependência não seria um problema, a não ser por perturbações, frutos da incerteza, que ocasionam problemas de adaptação nos participantes de transações via contratos incompletos.

Williamson (2005) define seis tipos de especificidade de ativos: a) a locacional, em que a proximidade economiza custos de transporte e armazenagem; b) a de ativos físicos, referente à especialização do ativo necessária para produzir o produto; c) a de ativos humanos, que se refere à necessidade de investimentos em capital humano para exercer a atividade; d) a de ativos dedicados, que são investimentos feitos para clientes específicos; e) a de marca, relacionada aos investimentos na marca de uma empresa e f) a temporal, na qual o valor da transação está relacionado ao tempo em que ela é processada, intimamente ligada a produtos perecíveis.

Para Williamson (1985), a especificidade dos ativos é o atributo de maior relevância para o estudo das estruturas de governança, pois, segundo Azevedo (1996), permite uma caracterização precisa e mensurável das relações. Os custos de transações estão diretamente ligados a todos esses fatores e influenciam os modos de coordenação adotados. No momento em que as empresas ajustam-se às características básicas das transações, elas minimizam os custos de transação.

\subsection{Análise institucional múltipla}

Williamson (2000) afirma que as empresas procuram sempre migrar dos arranjos institucionais menos eficientes para os mais eficientes, desde que os custos de implantação não ultrapassem os benefícios da economia. Nessa condição, em médio ou longo prazo, deve manter-se apenas o arranjo mais eficiente para determinada transação.

Entretanto, muitas pesquisas tratam da existência simultânea de vários arranjos institucionais num determinado setor, sem que houvesse tendência aparente de dominação progressiva de um deles. Ménard (1996, apud MIZUMOTO e ZYLBERSZTAJN, 2005), identificou três arranjos contratuais distintos coexistindo por mais de vinte anos na governança de um subsistema da avicultura de corte na França. Lafontaine e Shaw (2001) citam o exemplo das empresas de franquia, nas quais a proporção de lojas próprias e franqueadas varia fortemente em função das redes. Os autores concluem que a presença dos dois tipos de arranjos numa mesma empresa serve de equilíbrio entre incentivos via mercado e controle via hierarquia, o que permite à empresa beneficiar-se dos dois sistemas. Eccles (1981, apud MENARD, 2004) cita o caso de 38 empresas de construção, em que $80 \%$ das terceirizadas eram selecionadas através de negociações e $20 \%$, por licitação, e afirma que as empresas utilizam os dois arranjos em paralelo, para manter pressões mercadológicas sobre as empresas contratadas por negociação.

Mizumoto e Zylbersztajn (2005) justificam a coexistência de arranjos pelos efeitos complementares entre eles, ainda que isso ocasione custos de 
coordenação e investimentos de adaptação. No Brasil, Zylbersztajn e Nogueira (2002) e Mizumoto e Zylbersztajn (2005) analisaram a coexistência de diferentes arranjos institucionais para a mesma transação. Para Mizumoto e Zylbersztajn (2005), a melhor estratégia pode não ser simplesmente a escolha do arranjo mais eficiente, mas o estabelecimento de diversos arranjos simultâneos. O foco deixa de ser a decisão dicotômica make or buy para avançar nas razões que levam as firmas ao make and buy.

Segundo Zylbersztajn e Nogueira (2002), a análise institucional comparativa consiste na comparação direta de formas alternativas de governança em função da influência das instituições e das características das transações. Os autores afirmam que a existência de vários arranjos significa descontinuidade, sendo que a pesquisa deve se preocupar em avaliar os fatores responsáveis por isso. $\mathrm{O}$ fato de as características das transações serem similares num mesmo setor de atividade deve levar a arranjos institucionais iguais. A presença de vários tipos de arranjos pode ser explicada por variações no ambiente institucional, dependência de rota, ou ainda pela existência de rotinas específicas e não transferíveis, sem mencionar a situação de ajuste entre formas de governança atuais e futuras, movidas por modificações nas características das transações, o que configura uma situação de desequilíbrio.

Para Zylbersztajn e Nogueira (2002), os arranjos contratuais podem ser copiados e difundidos entre agentes que atuam em determinado sistema de produção. No entanto, sua difusão não ocorre de modo simétrico e contínuo. Para os autores, é importante compreender o processo que leva a taxas de adoção diferentes no mesmo sistema de produção.

\section{Metodologia de pesquisa}

Foram visitadas 37 fecularias nos três maiores estados produtores de fécula do Brasil: São Paulo, Paraná e Mato Grosso do Sul. Juntos, esses estados representavam 95\% da produção nacional em 2008 (ABAM, 2010). As visitas foram realizadas entre 2004 e 2005. Cada empresa analisada caracteriza uma unidade de produção, mas alguns grupos podem possuir várias unidades. As empresas visitadas representavam mais de $75 \%$ da produção nacional de fécula.

Para permitir a avaliação de características regionais, as empresas foram agrupadas em regiões: noroeste do Paraná (Paranavaí, Loanda), centro do Paraná (Campo Mourão), oeste do Paraná (Marechal Cândido Rondon), Mato Grosso do Sul (Ivinhema) e São Paulo (região de Assis). A totalidade das fecularias presentes nas regiões avaliadas foi visitada e apenas duas delas não responderam aos questionários. 


\subsection{Seleção das variáveis de desempenho}

A fécula de mandioca é uma commodity e o preço é o referencial principal para a comercialização. Os preços de mandioca e de fécula são diretamente relacionados à oferta de matéria-prima, e a falta de mandioca ocasiona perda de competitividade para o setor ${ }^{3}$. Grandes variações cíclicas de preços e oferta são fatores que prejudicam a imagem do setor e ocasionam perdas de mercado. Em consequência, a estabilidade da produção, que passa pelo controle do abastecimento dentro de uma empresa, pode ser considerada o principal critério de desempenho no setor. De nada adianta possuir os menores custos de produção, se falta matéria-prima a cada 18 meses.

Goebel (2005) confirma a importância dessa variável ao afirmar a necessidade de atuar de forma constante no mercado, com produto de preços atrativos, e enfatizar o prejuízo causado pelas constantes oscilações de oferta de matéria-prima para a competitividade das indústrias no mercado internacional.

As variáveis de desempenho selecionadas para análise, baseadas no objetivo de pesquisa, devem permitir a identificação de variações de abastecimento nas empresas, variações que serão relacionadas com o tipo de arranjo institucional adotado. As variações de preço e de oferta, apesar de relevantes, afetam o setor como um todo e não podem ser utilizadas na análise. A variável selecionada foi a capacidade das empresas em estabilizar sua produção, medida por meio da variação da produção entre um ano de grande disponibilidade (ano bom) e ano de baixa disponibilidade de matéria-prima (ano ruim). Essa variável permite introduzir o efeito do tempo e medir a evolução da oferta nas empresas.

$\begin{aligned} & \text { Variação da produção (\%) } \\ & \text { (VAR.PRO.) }\end{aligned}=\frac{\text { Produção ano bom - Produção ano ruim }}{\text { Produção ano bom }}$

A avaliação do grau de adaptabilidade de uma empresa deve ser realizada em ambiente perturbado, no qual há necessidade de mudança. O setor de mandioca caracteriza-se por grandes variações de preços e de quantidade de matéria-prima disponível. É possível considerar que as empresas que obtiveram menor variação de produção entre dois períodos opostos apresentam melhor adaptabilidade. Nesse caso, a empresa consegue melhor controle de sua produção, e pode abordar o mercado em condições mais favoráveis.

A adaptabilidade é considerada por Williamson (2005) como o problema central da organização econômica. A economia das governanças deve preocupar-

3 É importante ressaltar que a variação de produção ligada a fatores climáticos é reduzida nas regiões de produção de fécula. Assim, as variações na disponibilidade de mandioca refletem diretamente a área plantada, fator ligado ao preço da cultura no momento do plantio. 
Desempenho dos Arranjos Institucionais e Minimização dos Custos de Transação: transações entre produtores e fecularias de mandioca

-se com a avaliação da capacidade dos arranjos institucionais alternativos em se adaptar às mudanças.

\subsection{Classificação dos modos de coordenação}

No Brasil, as relações entre produtores e transformadores de mandioca são marcadas pela grande variedade de soluções, muitas vezes baseadas em contatos informais. A maioria das relações ocorre no mercado, sem contratos, mas com alta probabilidade de repetição futura.

Os modos de coordenação foram classificados em seis grupos, de acordo com o nível de garantias oferecidas em relação ao fornecimento de matéria-prima.

C1. Mercado "spot": não oferece nenhuma garantia aos intervenientes;

C2. Mercado com garantias informais: transações no mercado entre atores que se conhecem e que mantêm contatos regulares. Essa forma de coordenação é particularmente presente quando o industrial conhece pessoalmente os produtores agrícolas, o que permite a criação de vínculos privilegiados.

C3. Acordos contratuais com garantias fracas: os contratos elaborados podem ser formais ou não, mas sempre se caracterizam pelos baixos níveis de garantias. Um sistema contratual comum é a assinatura, por parte do industrial, de um compromisso de compra, com objetivo apenas burocrático. Esses contratos entre agricultores e industriais servem de garantia para o Banco do Brasil, que os exige para liberar os financiamentos de custeio. Na prática, eles não garantem a entrega da matéria-prima para a empresa.

C4. Acordos contratuais com garantias intermediárias: como no caso anterior, esses contratos podem ser formais ou não, mas a probabilidade de respeitar o acordo é maior que em C3. Esses arranjos consistem na compra antecipada da mandioca, ou no financiamento da cultura com reembolso em matéria-prima. O ponto negativo reside na fraqueza das garantias, tanto no caso de contratos formais quanto nos informais. Em caso de desrespeito aos acordos, os meios à disposição do industrial para recuperar seu investimento são de difícil aplicação.

C5. Acordos contratuais com garantias fortes (parceria): nessa coordenação, parte da mandioca produzida pelo agricultor vai para a empresa. Os industriais e os produtores participam juntos da produção, com divisão final do produto. O sistema mais comum é o sistema a meia, no qual a empresa oferece a terra e o preparo do solo, e o agricultor, o cultivo, e cada um fica com metade da produção. No caso de desobediência, o produtor perde sua credibilidade e não encontra mais terras para cultivar nos anos seguintes. 
C6. Integração vertical: os sistemas de garantia total são encontrados somente nos sistemas formais. Apenas uma coordenação preenche esse papel, a integração vertical, em que o empresário produz sua própria matéria-prima.

Os sistemas de governança diferenciam-se de acordo com as garantias oferecidas, que podem ser formais ou informais. As governanças C3 e C4 apóiam-se em garantias que misturam essas características. A baixa eficácia dessas garantias não permite grande segurança nos compromissos assumidos, obtida em contratos com garantias mais fortes, sejam formais ou não (C5), e na integração vertical. Em função do grau de confiança entre agricultores e industriais, o modo de coordenação no mercado e com garantias informais (C2) aproxima-se ou do mercado (C1), ou dos acordos contratuais com garantias fracas (C3). Como afirmado por Williamson (1985), as governanças via hierarquia (C6) são aquelas que oferecem os maiores níveis de garantia.

\subsection{Instrumentos estatísticos usados na identificação do desempenho dos arranjos institucionais}

Em função da hipótese de pesquisa, os arranjos institucionais adotados pelas empresas podem não ser os que permitem o melhor controle de abastecimento, e por consequência, a melhor estabilidade do setor. Para verificar isso, é indispensável verificar a influência dos diferentes arranjos encontrados nas empresas visitadas sobre a variável de desempenho adotada (variação da produção). A maioria das fecularias utiliza diferentes tipos de arranjos, alguns presentes em poucas empresas, o que dificulta a análise estatística.

A metodologia utilizada no trabalho, para o agrupamento dos arranjos institucionais em função do desempenho, foi a classificação automática e um sistema métrico. Essa classificação consiste em agrupar os indivíduos em classes cada vez mais gerais (FENELON, 1981). Para Volle (1997), os resultados de uma classificação dependem de uma série de escolhas, a primeira sendo a seleção do método de avaliação da distância entre os elementos do conjunto avaliado. $\mathrm{Na}$ pesquisa, as medidas foram realizadas a partir da distância euclidiana, técnica de agrupamento que representa a distância geométrica no espaço multidimensional.

Para colocar um mesmo peso para todas as variáveis, foi realizada a estandardização destas antes da análise ${ }^{4}$. A metodologia de agregação escolhida foi a agregação pela média (FENELON, 1981), ou unweighted pair-group average, que efetua o agrupamento entre um indivíduo e um grupo a partir da distância

4 A estandardização foi realizada a partir das variáveis centradas e reduzidas: $\mathrm{Z}=(\mathrm{X}$ - média. $\mathrm{X})$ / Desvio padrão. 
Desempenho dos Arranjos Institucionais e Minimização dos Custos de Transação: transações entre produtores e fecularias de mandioca

média entre o indivíduo e todos os membros do grupo (CATAENO, 1996). Essa estratégia de agregação apresenta a vantagem de evitar representações extremas, o que a torna a metodologia de agregação mais utilizada (CURI, 1991, apud CATAENO, 1996).

A classificação automática foi complementada por uma análise fatorial em componentes principais (ACP), que, para a classificação automática, agrupa as variáveis em função de suas distâncias respectivas.

Os resultados obtidos dependem de um grande número de variáveis, que se apresentam como uma nuvem de pontos impossível de representar em sua totalidade num plano em duas dimensões. O objetivo da ACP é simplificar esses resultados com a redução do número de dimensões a serem consideradas, e a menor perda possível de graus de precisão. Essa representação é realizada através de eixos fatoriais, ou principais. Um eixo é uma reta que atravessa a nuvem de pontos. O primeiro eixo fornece o máximo de informações, o segundo permite a segunda maior quantidade de informações etc. $O$ plano que menos deforma a realidade contém os dois primeiros eixos da nuvem (FENELON, 1981).

A interpretação dos resultados é facilitada no momento em que os primeiros eixos fornecem o máximo de informações sobre as variáveis de interesse, que, na pesquisa, é a de desempenho. Os eixos atravessam a nuvem de pontos em seu lugar de maior dispersão. Assim, para aumentar a participação da variável de desempenho na elaboração do primeiro eixo, é necessário dar a essa variável a maior dispersão possível. A variável de desempenho foi dividida em duas, uma de desempenho alto e uma de baixo, com uso de uma metodologia de classificação automática qualificada de segmentação por Fenelon (1981). Os indivíduos (empresas) foram agrupados de modo a maximizar a variância entre grupos e minimizar as diferenças dentro de um mesmo grupo. A separação dos indivíduos entre desempenhos alto e baixo permitiu estabelecer variáveis distantes, com grande participação na construção do primeiro componente da análise.

Essa segmentação permitiu diferenciar os arranjos institucionais que se aproximaram mais da variável de alto desempenho dos arranjos mais próximos à de baixo.

\section{Resultados e discussão}

Os resultados identificam os arranjos institucionais mais adotados e os que permitem melhor desempenho das empresas, ou seja, um abastecimento mais regular. 


\subsection{Arranjos institucionais nas transações de mandioca entre produtores e fecularias e relação com as características das transações}

De acordo com a economia dos custos de transação, os modos de coordenação escolhidos minimizam os custos de transação e são os mais eficientes possíveis.

Tabela 1. Porcentagens das transações de mandioca feitas por tipo de arranjo institucional.

\begin{tabular}{lcccccc}
\hline \multicolumn{1}{c}{ Governanças } & C1 & C2 & C3 & C4 & C5 & C6 \\
\hline Percentagem das transações & 31 & 26 & 18 & 6 & 2 & 13 \\
Percentagem das empresas que usam esse arranjo & 92 & 95 & 73 & 41 & 16 & 41 \\
\hline
\end{tabular}

Fonte: Resultados de pesquisa.

Os resultados indicam que as empresas escolhem principalmente os arranjos institucionais sem garantias (C1 e C2) (Tabela 1), seguidos dos acordos contratuais com garantias fracas (C3). Esses arranjos representavam $75 \%$ das transações realizadas pelas fecularias de mandioca na compra da matéria-prima, na época da análise, e eram utilizados por mais de $90 \%$ das empresas.

É importante ressaltar a grande diversidade nos arranjos institucionais adotados pelas empresas. Tradicionalmente, nos sistemas agroindustriais com vários tipos de arranjos institucionais, podem ser encontrados dois tipos de alternativas: os arranjos encontram-se em empresas diferentes, ou vários arranjos encontram-se na mesma empresa, para atender canais de distribuição diversos, como nas empresas de processamento de frango pesquisadas por Mizumoto e Zylbersztajn (2005), ou para manter o incentivo do mercado, como nas empresas de franquia avaliadas por Lafontaine e Shaw (2001).

No caso do setor de fécula de mandioca, todas as empresas trabalham com vários arranjos, com $54 \%$ delas utilizando simultaneamente pelo menos quatro dos seis arranjos apresentados na Tabela 1. A combinação de vários arranjos possui apenas um objetivo, o de maximizar o abastecimento de matéria-prima. A proporção de adoção de cada arranjo varia muito de um ano para outro, o que indica um sistema pouco estabilizado, que ainda procura um arranjo eficiente para o fornecimento de matéria-prima.

A produção de mandioca não exige mão de obra qualificada, tanto na produção agrícola quanto na industrial, por isso não há especificidade de ativos humanos. Podem ser encontrados ativos dedicados na produção de amido modificado, com mercado específico para um determinado cliente. No entanto, nas transações de mandioca entre produtores e fecularias não existem ativos dedicados. 
Desempenho dos Arranjos Institucionais e Minimização dos Custos de Transação: transações entre produtores e fecularias de mandioca

Tabela 2. Especificidade dos ativos nas relações entre produtores de mandioca e fecularias.

\begin{tabular}{lcc}
\hline \multicolumn{1}{c}{ Características das transações } & Produtor & Industrial \\
\hline Especificidade dos ativos & $+/+$ & $+/++$ \\
- Locacional & + & + \\
- Temporal & 0 & 0 \\
- Ativos humanos & 0 & 0 \\
- Ativos dedicados & 0 & + \\
- Ativos físicos & 0 & 0 \\
- Marca & 0 & \\
\hline
\end{tabular}

Legenda: 0: sem especificidade; +: Especificidade moderada; ++: Grande especificidade.

Fonte: Resultados de pesquisa.

A produção de mandioca é cada vez mais mecanizada, com equipamentos dedicados a essa cultura. Mesmo assim, os equipamentos são relativamente simples, fáceis de revender e a atividade permanece muito dependente de mão de obra, o que limita a importância dos ativos físicos nos produtores. No caso do uso da terra, produtores não enfrentam especificidade de ativos físicos, pois suas instalações podem ser usadas para outras culturas, sem grandes dificuldades. No que refere às indústrias de processamento, suas unidades podem sem remanejadas para processar outras matérias-primas, como milho, mas com custo elevado e perda de qualidade. Sendo assim, a limitação do processamento a uma matéria-prima permite evidenciar a existência de especificidade de ativos físicos.

Como commodity, a fécula de mandioca é um produto padronizado em nível internacional e sua comercialização é baseada no preço. No que refere aos amidos modificados, os tipos de produtos encontrados nas empresas brasileiras são de base, com comportamento similar ao amido não modificado. Por isso, não existe especificidade de marca.

A raiz de mandioca é uma matéria-prima com grandes quantidades de água, o que aumenta o custo de transporte e com armazenamento limitado após a colheita. A dificuldade de transporte da mandioca diminui as opções de venda dos produtores e as de compra das empresas, ocasionando especificidade locacional. O nível dessa especificidade depende muito da localização de produtores e empresas. Nas regióes com maior concentração de empresas e/ou de produtores, os níveis de especificidades são menores. Goebel (2005) indica que a distância média de transporte da mandioca era em tomo de 55 quilômetros. Entretanto, para diminuir a capacidade ociosa, as empresas buscavam sua matéria-prima em distâncias maiores, o que resultava em custos adicionais.

A impossibilidade de armazenamento da mandioca ocasiona também especificidade temporal. A possibilidade de atrasar a colheita, deixando a mandioca na 
terra ${ }^{5}$, minimiza a influência dessa variável em período de grande oferta, pois o produtor tem a possibilidade de esperar vários meses para preços melhores. A única limitação para ele é a disponibilidade de capital de giro para esperar a colheita. Como a maioria dos produtores é de pequeno porte, essa necessidade é um gargalo significativo. No período de falta, a impossibilidade de armazenar a mandioca é um fator limitante para as empresas, pois essas não podem contar com estoques de matéria-prima, como no caso do milho.

Segundo a ECT, a existência de especificidade dos ativos, como verificado na Tabela 2, deveria levar os atores a buscar arranjos institucionais com maiores níveis de garantia, tais como os arranjos C5 e C6.

A incerteza é outra característica das transações que, segundo a ECT, interfere nos arranjos institucionais encontrados. Essa, no que refere ao fornecimento de mandioca, é grande, com variações anuais elevadas, que se devem essencialmente à variação na área plantada, com resposta direta aos preços praticados. Assim, períodos de preços altos seguem períodos de valores baixos, num intervalo de 12 a 18 meses (Figura 2), que corresponde a um ciclo de produção da cultura. A essas variações cíclicas, pode ser adicionada a influência do consumo de farinha, cujas indústrias utilizam a mesma matéria-prima e que possuem pólos de produção no Paraná, onde há maior quantidade de fecularia. Todas essas interferências aumentam a incerteza do setor, o que deveria incentivar a procura de alternativas de transação mais seguras.

Existe grande frequência de relação entre os participantes das transações, principalmente em função das especificidades locacional e temporal. Porém, essa frequência, última característica das transações identificada pela ECT, não se traduz em confiança entre produtores e industriais. A compra da mandioca é realizada por empregados e os contatos acontecem essencialmente na indústria, no momento da entrega da matéria-prima. Relações de confiança poderiam diminuir a necessidade de garantias e aumentar o recurso aos arranjos do tipo C2.

A análise das características das transações indica a necessidade de arranjos com maiores níveis de garantia, como meio de diminuir os custos de transação ocasionados pela especificidade dos ativos e incerteza. No entanto, os dados da Tabela 1 indicam que isso não corresponde à situação encontrada no setor, com preferência para soluções de mercado. A explicação para a diferença entre a realidade e a teoria vem do papel das instituições, conforme definição de North (1991).

Por ser uma atividade com grande necessidade de mão de obra, a cultura de mandioca é praticada essencialmente por produtores de pequeno e médio

5 Quando armazenada na terra, a mandioca continua seu crescimento, o que pode ser vantajoso para produtores. Assim, uma mandioca de 18 meses produz de 50 a $100 \%$ a mais que uma mandioca de 10 meses. 
Desempenho dos Arranjos Institucionais e Minimização dos Custos de Transação: transações entre produtores e fecularias de mandioca

porte. No caso da adoção de arranjos contratuais, as fecularias devem negociar com uma grande quantidade de parceiros, cada qual com contrato de valor reduzido. Em caso de desrespeito ao contrato pelo produtor, os custos judiciais podem ser mais altos que o valor em litígio, e o prazo para a decisão judiciária, longo demais para resolver os problemas de abastecimento da empresa. A pesquisa indicou que $70 \%$ dos empresários entrevistados não confiavam na justiça. Outro agravante é a ausência de bens dos produtores, que limita os valores a serem ressarcidos. Em todas as situações, as instituições não garantem a redução dos custos de transação dos acordos contratuais, o que diminui o tipo de garantia desse tipo de arranjo e explica a falta de interesse por parte das empresas.

Ménard (2004) indica que a incerteza é diretamente ligada ao ambiente institucional. $\mathrm{O}$ aumento da incerteza institucional indica o crescimento do risco contratual, com a necessidade de arranjos com maior nível de controle e dependência. Para o autor, essa situação leva as empresas a buscarem arranjos contratuais com maiores níveis de integração.

Nas transações entre produtores de mandioca e fecularias, com base na afirmação de Ménard, o arranjo esperado seria a integração vertical. Todavia, nessa alternativa, os custos de mão de obra são muito elevados, e as dificuldades de fiscalização da produção levam a produtividades muitas vezes reduzidas em relação a pequenos produtores independentes. O problema trabalhista é outro fator que diminui o interesse da integração e aumenta os custos de transação dessa alternativa.

A ineficiência institucional eleva os custos de transação dos contratos e da integração vertical, arranjo prejudicado também por problemas do tipo agenteprincipal, com dificuldade para fiscalizar as atividades da mão de obra no campo. Assim, transações que deveriam ser realizadas com arranjos institucionais de maior nível de garantias, segundo as características das transações, acabam sendo efetivadas com arranjos de baixo nível de garantia.

\subsection{Identificação dos arranjos institucionais com melhor desempenho}

A identificação do desempenho dos arranjos institucionais foi realizada por meio da Análise em Componentes Principais (ACP) apresentada na Figura 3. As variáveis de coordenação foram medidas a partir da porcentagem de mandioca fornecida pelo modo de coordenação considerado. 
Figura 3. Análise em Componentes Principais dos modos de coordenação e do desempenho, nas fecularias de mandioca analisadas.

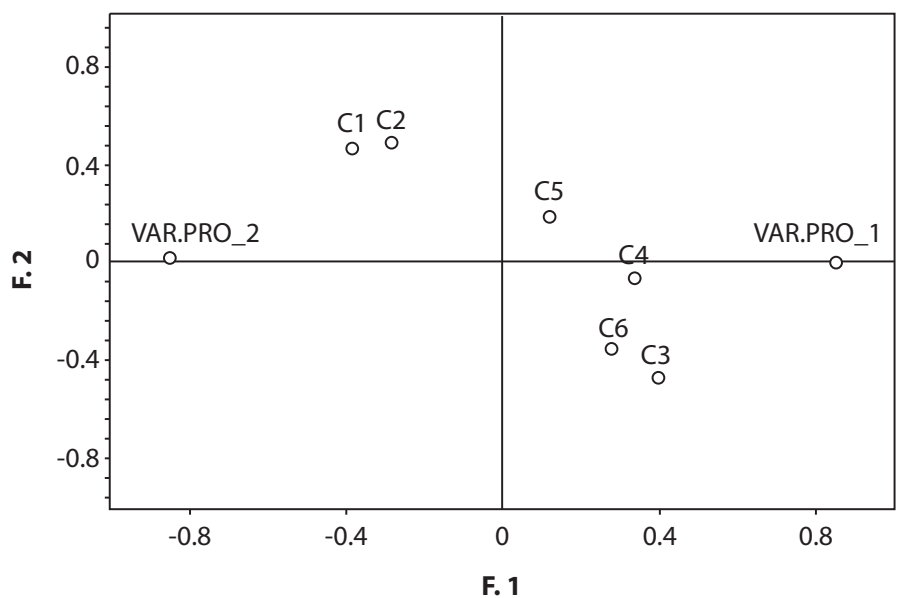

Variável de desempenho: Variação da produção positiva = VARPRO 1, negativa = VARPRO 2; Variáveis de governança (coordenação): aumento do nível de garantia da transação de C1 (mercado) para C6 (integração vertical).

Fonte: Resultados de pesquisa.

Nos resultados da ACP apresentados na Figura 3, o eixo 1 permite avaliar a relação entre os arranjos institucionais e a variável de variação de produção (adaptabilidade da empresa). Por meio da análise é possível verificar um efeito positivo dos sistemas de coordenação com garantias intermediárias (C3 e C4) e da integração vertical sobre a adaptabilidade das empresas. As coordenações com menos garantias (C1 e C2) apresentam um efeito negativo sobre essa variável.

A ACP forneceu informação incompleta, pois os dois primeiros eixos fatoriais explicaram apenas $43 \%$ da dispersão total das variáveis. Para melhorar a identificação dos modos de coordenação das fecularias, a Tabela 3 indica as distâncias euclidianas entre as variáveis de coordenação e de desempenho, obtidas na análise de classificação automática. Quanto menor a distância, melhor o desempenho do sistema de coordenação.

Tabela 3. Distâncias euclidianas entre a variável de desempenho e os arranjos institucionais adotados pelas fecularias avaliadas.

\begin{tabular}{lllllll}
\hline & C1 & C2 & C3 & C4 & C5 & C6 \\
\hline VAR. PRO. & 8,8 & 8,8 & 7,5 & 7,8 & 8,7 & 8,2 \\
\hline
\end{tabular}

Fonte: Resultados de pesquisa. 
Desempenho dos Arranjos Institucionais e Minimização dos Custos de Transação: transações entre produtores e fecularias de mandioca

Com os valores da Tabela 3, torna-se possível classificar os arranjos institucionais dos mais próximos até os mais distantes das variáveis de desempenho.

$$
\text { VAR. PRO.: } \mathrm{C} 3 \rightarrow \mathrm{C} 4 \rightarrow \mathrm{C} 6 \rightarrow \mathrm{C} 5 \rightarrow \mathrm{C} 1 \text { e C2 }
$$

Verifica-se que os acordos contratuais com garantias intermediárias (C3 e C4) foram os de melhor classificação, superiores aos arranjos com garantias mais fortes (C5 e C6), o que comprova os resultados da ACP. O recurso ao mercado (C1 e C2) tem ação negativa sobre a adaptabilidade das empresas. Arranjos com garantias fortes (C5 e C6) são menos flexíveis, o que pode prejudicar a adaptabilidade da empresa em relação aos arranjos do tipo C3 e C4 e explicar os resultados da pesquisa.

Os resultados permitem evidenciar que, apesar da desconfiança dos atores das transações em relação aos contratos, estes permitem um ganho no desempenho das empresas e facilitam a estabilização da produção.

\subsection{Fatores explicativos da adoção de arranjos institucionais múltiplos}

Para Zylbersztajn e Nogueira (2002), a existência de arranjos múltiplos simultâneos num mesmo setor pode ser explicada por variações no ambiente institucional, dependência de rota, ou ainda pela existência de rotinas específicas e não transferíveis. No caso do setor de mandioca, a maioria das empresas utiliza ou já utilizou diferentes tipos de arranjos institucionais, o que elimina as explicações a partir de rotinas específicas e de dependência de rota.

A produção brasileira de fécula de mandioca é concentrada em três estados. O Paraná lidera, com 62\% da produção nacional em 2008 (ABAM, 2010), frente ao sul do estado de Mato Grosso do Sul, com 19\%, e o sudoeste de São Paulo, com $14 \%$. Todas essas empresas estão localizadas em áreas próximas e estão sujeitas ao mesmo ambiente institucional. Sendo assim, esse fator não pode ser responsabilizado pelas diferenças entre as empresas.

Furubotn e Richter (2005) alegam que a seleção do arranjo institucional de maior eficiência aplica-se na economia neoclássica, mas é mais difícil de sustentar na NEI, em que os custos de transação ocupam grande relevância. Para os autores, os atores diferem em relação a suas habilidades, recursos iniciais, capacidade de informação, gosto pelo risco, entre outros, e enfrentam grande variedade de restrições que limitam suas opções. Furubotn e Richter (2005) afirmam que a sobrevivência de vários desses arranjos é possível, pois o importante é tão somente a eficiência relativa e não a ideal. A existência de custos de transação sempre dificulta a monitoração e a execução de todos os acordos legais e contratuais. Nesse ambiente, o que importa é aquilo que funciona, por isso entende-se a aparição simultânea de vários tipos de arranjos institucionais. 
No setor de fécula de mandioca, a justificativa da presença de muitos arranjos institucionais nas transações para compra de matéria-prima pode originar-se da diferença entre os arranjos institucionais de menores custos de transação via mercado do tipo $\mathrm{C} 1$-, e os que permitem maior estabilidade da produção - os acordos contratuais C3 e C4. Ocorre, então, uma oscilação contínua das empresas entre esses arranjos. A realização de transações via mercado significa maiores dificuldades de obtenção de matéria-prima, o que incentiva a empresa a recorrer a arranjos mais controlados, através de relações contratuais ou mesmo de integração vertical. Por outro lado, esses arranjos apresentam maiores custos de transação, devido à incerteza no funcionamento das instituições, que favorece o uso do mercado. Essa indefinição entre desempenho e custos de transação pode explicar a indecisão do setor e a presença de arranjos diferentes simultaneamente nas mesmas empresas.

\section{Conclusões}

Os resultados da pesquisa indicam que os sistemas de governança mais adotados pelas fecularias, com menores custos de transação, não são os de melhor desempenho geral. Um abastecimento que não permite boa estabilidade da oferta de matéria-prima tem efeito negativo sobre os custos de produção da empresa e sobre sua competitividade.

A melhoria do funcionamento de um setor de atividade passa pela maximização conjunta dos fatores de desempenho e dos custos de transação. Nos setores de transformação de mandioca, o abastecimento no mercado possui os menores custos de transação, mas também baixo desempenho, enquanto os acordos contratuais com garantias fracas e intermediárias (C3 e C4) são mais eficientes, mas possuem custos de transação superiores.

A busca de soluções para melhoria segue dois caminhos: (1) a melhora da eficiência do mercado, arranjo institucional que beneficia com custos de transação menores ou (2) a redução dos custos de transação de C3 e C4, para aproveitar a eficiência dessas governanças.

A redução dos custos de transação C3 e C4 envolve mudanças institucionais, com maior segurança no que diz respeito aos contratos assinados, e agilidade na solução dos conflitos entre os participantes das transações. Essa solução escapa do alcance das empresas e é de difícil implantação em curto prazo.

A melhoria da eficiência dos acordos via mercado exige o aumento do nível de garantia oferecido por esse tipo de arranjo. Essa solução foi adotada pela Tailândia, com a negociação de contratos de fécula de mandioca no mercado futuro daquele país (AFET, 2008). Nessa perspectiva, os contratos futuros permitem uma estimativa da evolução dos preços, que serve de base para as empresas planejarem suas compras no mercado. A existência de contratos 
Desempenho dos Arranjos Institucionais e Minimização dos Custos de Transação: transações entre produtores e fecularias de mandioca

futuros de fécula facilita também a realização de contratos de compra de mandioca com preço fixado, uma vez que esse é garantido pelos contratos futuros realizados pela empresa.

Enquanto nenhuma das soluções é adotada, as fecularias brasileiras continuam a utilizar, preferencialmente, arranjos de baixo custo de transação, mas com desempenho fraco, o que prejudica o setor como um todo, sem eliminar de vez arranjos mais eficientes, mas com maiores custos de transação.

\section{Referências Bibliográficas}

ABAM. Produção brasileira de amido de mandioca. Disponível em <www.abam. com.br>. Acesso em janeiro de 2010.

AFET-Agriculture Future Exchange of Thailand. Tapioca starch contract specification. Disponível em: <http://www.afet.or.th/english/product/ts/contractspec.php >. Acesso em dezembro de 2008.

AZEVEDO, P.F. Integração Vertical e Barganha. 1996. Tese (Doutorado em Economia) - Departamento de Economia da Faculdade de Economia, Administração e Contabilidade. São Paulo: Universidade de São Paulo, 1996.

CARDOSO, C.E.L. Competitividade e inovação tecnológica na cadeia agroindustrial de fécula de mandioca no Brasil. 2003. 188 p. Tese (Doutorado em Ciências) - Escola Superior de Agricultura “Luiz de Queiroz". Piracicaba: Universidade de São Paulo, 2003.

CATAENO, A. Aplicação de análise multivariada no estudo do comportamento da erosividade das chuvas no estado de São Paulo. 1996. 88 p. Tese (Livre Docência) Faculdade de Ciências Agrárias, Botucatu: UNESP, 1996.

CEPEA. Preços raiz, fécula e farinha de mandioca. CEPEA / ESALQ. Disponível em: $<$ http://www.cepea.esalq.usp.br/mandioca/> . Acesso em janeiro de 2010.

COASE, R. H. The Nature of the Firm. Economica, New Series, Vol. 4, No. 16. (Nov., 1937), pp. 386-405. Disponível em: <http://links.jstor.org/sici?sici=00130427\% 28193711\% 292\%3A4\%3A16\%3C386\%3ATNOTF\%3E2.0.CO\%3B2-B > . Acesso em janeiro de 2010.

FENELON, J.P. Qu'est-ce que l'analyse des données? Paris, Lefonen, 1981. p. 311.

FIANI, R. Teoria dos custos de transação. KUPFER, D.; HASENCLEVER, L. Economia industrial: fundamentos teóricos e práticos no Brasil. Rio de Janeiro, Elsevier, 2002. p. $267-286$.

FURUBOTN, E.G.F e RICHTER, R. Institutions e economic theory. The contribution of the New Institutional Economics. The University of Michigan Press, 2. edition, 2005. $653 \mathrm{p}$. 
GOEBEL, M.A. Organização e coordenação do sistema agroindustrial da mandioca na microregião Oeste do Paraná. 2005. 148 p. Dissertação (Mestrado em Desenvolvimento Regional e Agronegócio), Universidade Estadual do Oeste do Paraná - UNIOESTE, Toledo, 2005.

INSTITUTO BRASILEIRO DE GEOGRAFIA E ESTATÍSTICA - IBGE. Levantamento sistemático da produção agrícola (LSPA). Disponível em: <http://www.ibge.gov.br/ home/estatistica/indicadores/agropecuaria/lspa/defaulttab.sht $>$. Acesso em 11 fevereiro de 2010 .

LAFONTAINE, F.; SHAW, K. Targeting managerial control: evidence from franchising. National Bureau of Economic Research; NBER working paper; working paper 8416; August 2001. 41 p.

MÉNARD, C. The economics of hybrid organizations. Journal of Institutional and Theoretical Economics JITE, v. 160, n.3, p. 345-376 (32), 2004.

MIZUMOTO, F. M.; ZYLBERSZTAJN, D. Estratégia de Canais de Distribuição Múltiplos: Casos na Avicultura de Postura Brasileira. In: SEMINÁRIOS EM ADMINISTRAÇÃO, 8., São Paulo, 2005. São Paulo: Anais..., 2005.

NORTH, D.C. Institutions. The Journal of Economic Perspectives, v. 5, n. 1, p.97-112 1991.

PETERSON, H.C.; WYSOCKI, A.; HARSH, S.B. Strategic choice along the vertical coordination continuum. International Food and Agribusiness Management Review, Elsevier, v.4, p. 149-166, 2001.

PITELLI, M. M. Sistema agroindustrial brasileiro da carne bovina: análise do impacto das mudanças institucionais européias sobre a estrutura de governança. 2004. Dissertação (Mestrado), São Paulo: USP, 2004.

PONDE, J.L. Organização das grandes corporações. KUPFER, D. e HASENCLEVER, L. Economia industrial: fundamentos teóricos e práticos no Brasil. Rio de Janeiro, Elsevier, 2002. p. 287 - 306.

TAKITANE, I.C.; CEREDA, M.P.; CHUZEL,G. e VILPOUX, O. Starch potential in Brazil. In DUFOUR, D., O'BRIEN, G.M. e BEST, R. Cassava Flour and Starch: Progress in research and development. Cali, CIRAD e CIAT, 1996. p. 19 - 24.

VILPOUX, O. A cadeia de mandioca no Brasil. Campo Grande, SEBRAE - MS, 2006. 82 p.

VILPOUX, O. Etude des coordinations verticales entre entreprises transformatrices de manioc et producteurs agricoles au sud du Brésil. 1997. 233 p. Tese (Doutorado em Engenharia de Produção) - Institut National Polytechnique de Lorraine (INPL), Cergy-Pontoise (França), 1997.

VOLlE, M. Analyse des données. Paris, Economica, Collection Economie et Statistiques Avancées, 4. edição, 1997. 323 p. 
Desempenho dos Arranjos Institucionais e Minimização dos Custos de Transação: transações entre produtores e fecularias de mandioca

WILLIAMSON, O. The Economic Institutions of Capitalism. New York, The Free Press, 1985. $450 \mathrm{p}$.

WILLIAMSON, O.E. Why law, economics, and organization? UC Berkeley School of Law Public Law and Legal Theory; Working Paper No. 37; 2000. p. 48. Disponível em: < http://papers.ssrn.com/paper.taf?abstract_id=255624>. Acesso em 04 de janeiro de 2010.

WILLAMSON, O.E. The Economics of Governance. University of California, Berkeley, January 2005. p. 49. Disponível em: < http://www.aeaweb.org/annual_ mtg_papers/2005/0107_1645_0101.pdf > . Acesso em 04 de janeiro de 2010.

ZYLBERSZTAJN, D.; NOGUEIRA, A.C.L. Estabilidade e difusão de arranjos verticais de produção: uma contribuição teórica. Economia e Sociedade, Campinas, v. 11, n. 2, f.19, p. 329-346, jul./dez. 2002. 